\title{
Ocular biomarkers for cognitive impairment in nonagenarians; a prospective cross- sectional study
}

Jacoba A. van de Kreeke ${ }^{1 *}$, Nienke Legdeur ${ }^{2}$, Maryam Badissi ${ }^{2}$, H. Ton Nguyen ${ }^{1}$, Elles Konijnenberg ${ }^{2}$, Jori Tomassen², Mara ten Kate ${ }^{2}$, Anouk den Braber ${ }^{2,3}$, Andrea B. Maier ${ }^{4,5}$, H. Stevie Tan ${ }^{1}$, Frank D. Verbraak and Pieter Jelle Visser ${ }^{2}$

\begin{abstract}
Background: Ocular imaging receives much attention as a source of potential biomarkers for dementia. In the present study, we analyze these ocular biomarkers in cognitively impaired and healthy participants in a population aged over 90 years (= nonagenarian), and elucidate the effects of age on these biomarkers.

Methods: For this prospective cross-sectional study, we included individuals from the EMIF-AD 90+ study, consisting of a cognitively healthy $(N=67)$ and cognitively impaired group $(N=33)$, and the EMIF-AD PreclinAD study, consisting of cognitively healthy controls aged $\geq 60(N=198)$. Participants underwent Optical Coherence Tomography (OCT) and fundus photography of both eyes. OCT was used to asses total and individual inner retinal layer thickness in the macular region (Early Treatment Diabetic Retinopathy Study circles) as well as peripapillary retinal nerve fiber layer thickness, fundus images were analyzed with Singapore I Vessel Assessment to obtain 7 retinal vascular parameters. Values for both eyes were averaged. Differences in ocular biomarkers between the 2 nonagenarian groups were analyzed using linear regression, differences between the individual nonagenarian groups and controls were analyzed using generalized estimating equations.
\end{abstract}

Results: Ocular biomarkers did not differ between the healthy and cognitively impaired nonagenarian groups. 19 out of 22 ocular biomarkers assessed in this study differed between either nonagenarian group and the younger controls.

Conclusion: The ocular biomarkers assessed in this study were not associated with cognitive impairment in nonagenarians, making their use as a screening tool for dementing disorders in this group limited. However, ocular biomarkers were significantly associated with chronological age, which were very similar to those ascribed to occur in Alzheimer's Disease.

Keywords: Retina, Optical coherence tomography, Fundus photography, Singapore I vessel assessment, Nonagenarians, Ocular biomarkers, Cognitive impairment

\footnotetext{
* Correspondence: ja.vandekreeke@amsterdamumc.nl

'Ophthalmology Department, Amsterdam UMC, location VUmc, De Boelelaan 1117, 1081HV Amsterdam, The Netherlands

Full list of author information is available at the end of the article
}

(c) The Author(s). 2020 Open Access This article is licensed under a Creative Commons Attribution 4.0 International License, which permits use, sharing, adaptation, distribution and reproduction in any medium or format, as long as you give appropriate credit to the original author(s) and the source, provide a link to the Creative Commons licence, and indicate if changes were made. The images or other third party material in this article are included in the article's Creative Commons licence, unless indicated otherwise in a credit line to the material. If material is not included in the article's Creative Commons licence and your intended use is not permitted by statutory regulation or exceeds the permitted use, you will need to obtain permission directly from the copyright holder. To view a copy of this licence, visit http://creativecommons.org/licenses/by/4.0/ The Creative Commons Public Domain Dedication waiver (http://creativecommons.org/publicdomain/zero/1.0/) applies to the data made available in this article, unless otherwise stated in a credit line to the data. 


\section{Background}

The eye, and more specifically the retina, shares many similarities with the brain. Both are derived from the same embryological tissue and consist of a complex combination of neuronal tissue and glial cells $[1,2]$. One could consider the retina to be an extension of the brain $[1,2]$. Assessment of the retina may provide information on diseases causing cognitive impairment, such as Alzheimer's disease (AD). Therefore, studies have been performed on the diagnostic value of optical techniques used to examine the retina in $\mathrm{AD}$, as these ocular markers may be less invasive and cheaper than most established biomarkers for brain diseases [3-8].

There is ample evidence of retinal changes in dementia [3-8]. In AD, retinal thinning has been observed on Optical Coherence Tomography (OCT), especially of the inner layers $[3,5]$. Studies have also shown differences between individuals with and without dementia in the (micro)vascular state of their retinal vessels (such as vessel width, tortuosity and fractal dimension) through fundus photography, although these results were sometimes contradicting [8-11].

It is estimated that up to $40 \%$ of individuals aged 90 and over suffer from dementia and as such, this group is an important target group for potential new biomarkers for dementia [12]. In nonagenarians (individuals between the ages of 90-100), dementia is mostly caused by mixed pathologies, including $\mathrm{AD}$ and vascular brain damage $[13,14]$. This may be reflected in the retinal biomarkers, causing the expected changes due to for example AD (retinal thinning and changes in microvasculature) to be less discriminative in this older population compared to younger individuals. Furthermore, many of the changes occurring in the retina of individuals with dementia also occur naturally with the aging process $[15,16]$. These factors could mean that ocular biomarkers are much less suitable in a significantly aged group.

In this cross-sectional study, we aimed to 1) investigate whether retinal (layer) thickness and retinal vascular parameters differ between cognitively healthy and cognitively impaired nonagenarians and 2) elucidate the effects of age on these ocular biomarkers.

\section{Methods}

\section{Participants}

This study consists of combined data from 2 Amsterdam UMC sub-studies of the European Medical Information Framework for Alzheimer's Disease (EMIF-AD): the EMIF-AD 90+ study and the EMIF-AD PreclinAD cohort. The $90+$ study consists of cognitively healthy and cognitively impaired subjects, aged $\geq 90$ or over. For extensive recruitment information we refer to our set-up paper of this study by Legdeur et al. [17]. The PreclinAD cohort [18] is a cohort consisting of cognitively healthy participants (monozygotic twins) aged $\geq 60$, recruited from the Netherlands Twin Registry [19]. The studies adhered the Tenets of the Declaration of Helsinki and written informed consent was obtained from all participants. The Medical Ethics Committee of the Amsterdam UMC approved both studies.

For complete in- and exclusion criteria of the EMIFAD 90+ study, we refer to our set-up paper of this study by Legdeur et al. [17]. In short, inclusion criteria for the cognitively normal group of the $90+$ study were: age $\geq$ 90 years and cognitively healthy This group is referred to as 'healthy nonagenarian' group.

Inclusion criteria for individuals with cognitive impairment (CI) of the 90+ study were: a diagnosis of amnestic Mild Cognitive Impairment (aMCI) [20] or a diagnosis of probable or possible AD [21]. As during the study we had difficulties identifying subjects of 90 years and older with aMCI or probable or possible $\mathrm{AD}$, we broadened the inclusion criteria in this group to subjects older than 85 years. Six individuals from this group were aged $85-$ 90 years. This group is referred to as 'CI nonagenarian' group.

Inclusion criteria for the PreclinAD study were: age $\geq$ 60 years, monozygosity and cognitively healthy. For complete in-/exclusion criteria we refer to the set-up paper of this study by Konijnenberg et al. [18]. This group is referred to as the 'control' group.

From the total 298 participants included in the cohorts, 51 (17.1\%) participants were excluded for both the OCT and SIVA analyses, but these were not necessarily the same participants, although there was a high overlap. For the OCT analyses, 9 were excluded due to low quality scans/failed imaging and 42 due to ophthalmological pathology. For the SIVA analyses, 24 were excluded due to low quality images/failed imaging and 27 due to ophthalmological pathology. Interfering ophthalmological pathology consisted mostly of glaucoma and (severe) AMD. Additional file 1 shows the reasons for exclusion in more detail, categorized per group (control, heathy nonagenarian and CI nonagenarian). Although the two study populations (i.e. for OCT and SIVA analyses) were slightly different from each other in terms of included individuals, they were very similar in their demographics, and statistical analyses revealed no significant differences. As such, their demographic information was reported as one combined group.

\section{Medical history}

Data about the medical and family history and medication use, in particular on the presence of diabetes mellitus, hypertension and coronary disease, were collected through a structured interview, in combination with information provided by the study partner (if available), general practitioner and/or medical specialist. 


\section{Ophthalmological examination}

All participants underwent the following ophthalmological examinations: best corrected visual acuity, intraocular pressure, refraction data, slit lamp examination, indirect fundoscopy, fundus photography and OCT. Controls received tropicamide $0.5 \%$ to enable these examinations, nonagenarians both tropicamide $0.5 \%$ and phenylephrine $5 \%$ (as mydriasis was harder to achieve in these very aged patients). If a nonagenarian suffered from coronary stenosis, only tropicamide was given, due to the slight risk of phenylephrine inducing a coronary spasm. All photographs/OCT images were assessed by an experienced ophthalmologist (HTN or FDV) for unexpected pathology. Participants suffering from ophthalmological conditions severely interfering with the (neuro)retina or image quality were excluded from analyses (severe cataract, macular degeneration, glaucoma, diabetic retinopathy, vascular occlusions). Eyes with diseases considered to interfere with the OCT measurements excluded from OCT analyses could still be included in the SIVA analyses and vice versa (e.g. AMD with geographical atrophy interfered with OCT, but not fundus image analyses). This resulted in a slightly different study population for the OCT and SIVA analyses.

\section{Optical coherence tomography}

Using spectral domain OCT (Spectralis, Heidelberg), dense macular scans (49 B-scans) and axonal ring scans around the optic nerve head $(\mathrm{ONH})$ were acquired. Total retinal thickness and individual layer thickness was measured in the macular region. The following individual retinal layers were analyzed: retinal nerve fiber layer (RNFL), ganglion cell layer (GCL) and inner plexiform layer (IPL). A distinction was made between the inner and outer macular ring according to the standard Early
Treatment and Diabetic Retinopathy Study (ETDRS) macular grid (1-3 $\mathrm{mm}$ around the fovea for inner ring and 3-6 $\mathrm{mm}$ around the fovea for outer ring). For further details on the acquiring of OCT data we refer to our earlier paper by van de Kreeke et al. [22].

\section{Fundus photography and quantitative assessment of retinal vasculature}

Digital fundus images were made of the fundus of both eyes in all participants (Topcon TRC 50DX type IA). All images were graded by a trained grader (JAvdK) using the Singapore I Vessel Assessment (SIVA) software (version 3.0, National University of Singapore, Singapore) [9-11]. The following 7 retinal vascular parameters were analyzed: central retinal artery equivalent (CRAE), central retinal vein equivalent (CRVE), arteriole-venular ratio (AVR), fractal dimension of the arteriolar network (FDa), fractal dimension of the venular network (FDv), curvature tortuosity of the arterioles (cTORTa) and curvature tortuosity of the venules (cTORTv). All values for retinal vascular parameters were measured within zone $C$ (i.e. 0.5-2 disc diameters around the optic nerve head). For further information on the analyses of fundus images we refer to our earlier paper by van de Kreeke et al. [23].

\section{Statistical analysis}

First, we compared group means of all ocular outcome measures of the healthy and CI nonagenarian groups using linear regression, corrected for age, sex and diabetes. Additionally, mean differences between both nonagenarian groups and younger healthy controls were obtained using Generalized Estimating Equations (GEE). GEE was used to correct for clustering in the data from twin pairs in de control group. It also allowed us to

Table 1 Demographics of the study population

\begin{tabular}{llll}
\hline & Controls & Healthy nonagenarians & Cl nonagenarians \\
\hline OCT analyses N & 172 & 52 & 23 \\
SIVA analyses N & 173 & 50 & 24 \\
Age (years) & $70.4( \pm 7.5)$ & $92.4( \pm 1.9)$ & $91.9( \pm 2.9)$ \\
Sex, female N (\%) & $105(57.4 \%)$ & $30(52.6 \%)$ & $20(74.1 \%)$ \\
BCVA (LogMAR) & $0.02( \pm 0.10)$ & $0.14( \pm 0.21)$ & $0.13( \pm 0.22)$ \\
Intra-ocular pressure (mmHg) & $14.4( \pm 2.8)$ & $15.9( \pm 2.0)$ & $15.6( \pm 2.2)$ \\
Spherical equivalent & $0.28( \pm 1.86)$ & $-0.02( \pm 1.41)$ & $0.05( \pm 0.13)$ \\
MMSE (median, IQR) & $29.0(29.0-30.0)$ & $29.0(28.0-30.0)$ & $24.0(20.0-26.0)$ \\
Hypertension N (\%) & $75(41.0 \%)$ & $23(40.4 \%)$ & $16(59.3 \%)$ \\
Diabetes mellitus N (\%) & $8(4.4 \%)$ & $3(5.3 \%)$ & $2(7.4 \%)$ \\
Coronary disease N (\%) & $18(9.8 \%)$ & $14(24.6 \%)$ & $7(25.9 \%)$ \\
\hline
\end{tabular}

Data are means from the groups combined unless otherwise specified

CI Cognitively Impaired, N Number of participants, OCT ptical Coherence Tomography, SIVA Singapore I Vessel Assessment, BCVA Best Corrected Visual Acuity, MMSE Mini-Mental State Exam, IQR Inter-Quartile Range, CERAD Consortium to Establish a Registry for Alzheimer's Disease. Coronary disease in this case means a history of myocardial infarction or angina pectoris 
correct for confounders such as sex and a diagnosis of diabetes. We deliberately did not correct this analysis for age, to illustrate the differences based on aging effects. Curvature tortuosity (cTORT) values for arteries and veins were log-transformed to normalize their distribution. All statistical analyses were performed using SPSS (IBM, version 22).

\section{Results}

Table 1 shows the demographics of the combined study populations (for OCT and SIVA both) included for analyses.

When comparing the two nonagenarian groups, no significant differences in any of the ocular biomarkers were found (Table 2).

Both the healthy and the CI nonagenarians differed significantly in multiple ocular biomarkers when compared to the younger control group, with most ocular parameters being lower in the nonagenarian groups. 4 out of 22 biomarkers assessed differed significantly between healthy nonagenarians and younger controls, 1 out of 22 differed between CI nonagenarians and younger controls, and 14 out of 22 differed between both CI and healthy nonagenarians compared to younger controls. Figures 1 and 2 show boxplots for the 3 groups, Table 3 shows the mean differences of both nonagenarian groups compared to the control group, corrected for twin dependencies, sex and diabetes.

\section{Discussion}

Ocular biomarkers showed no differences between cognitively healthy and cognitively impaired nonagenarians. However, nonagenarians did show extensive differences in their ocular biomarkers when compared to a younger control group, which were very similar to changes often attributed to $\mathrm{AD}$ in existing literature.

Table 2 Differences between means for ocular biomarkers in both the healthy and the $\mathrm{Cl}$ nonagenarian groups

\begin{tabular}{|c|c|c|c|c|}
\hline & Healthy nonagenarians & $\mathrm{Cl}$ nonagenarians & SE & $p$-value \\
\hline \multicolumn{5}{|l|}{ Macular retinal layer thickness: } \\
\hline Total RT inner ring $(\mu \mathrm{m})$ & 323.5 & 317.3 & 5.0 & 0.218 \\
\hline Total RT outer ring $(\mu \mathrm{m})$ & 282.2 & 276.1 & 4.0 & 0.133 \\
\hline RNFL inner ring $(\mu \mathrm{m})$ & 23.0 & 22.2 & 0.8 & 0.353 \\
\hline RNFL outer ring $(\mu \mathrm{m})$ & 36.4 & 35.5 & 1.4 & 0.518 \\
\hline $\mathrm{GCL}$ inner ring $(\mu \mathrm{m})$ & 43.9 & 42.9 & 1.6 & 0.550 \\
\hline GCL outer ring $(\mu \mathrm{m})$ & 30.0 & 29.9 & 1.1 & 0.940 \\
\hline IPL inner ring $(\mu \mathrm{m})$ & 36.6 & 35.5 & 1.0 & 0.275 \\
\hline IPL outer ring $(\mu \mathrm{m})$ & 25.5 & 24.9 & 0.8 & 0.449 \\
\hline \multicolumn{5}{|l|}{ Peripapillary RNFL: } \\
\hline Average $(\mu \mathrm{m})$ & 88.3 & 89.1 & 2.7 & 0.762 \\
\hline Nasal superior ( $\mu \mathrm{m})$ & 90.6 & 96.6 & 4.9 & 0.229 \\
\hline Nasal ( $\mu \mathrm{m})$ & 67.1 & 69.9 & 3.5 & 0.428 \\
\hline Nasal inferior $(\mu \mathrm{m})$ & 101.9 & 102.3 & 5.3 & 0.940 \\
\hline Temporal inferior ( $\mu \mathrm{m})$ & 123.0 & 122.1 & 5.2 & 0.868 \\
\hline Temporal $(\mu \mathrm{m})$ & 69.1 & 66.9 & 3.2 & 0.471 \\
\hline Temporal superior $(\mu \mathrm{m})$ & 118.9 & 118.0 & 4.5 & 0.854 \\
\hline \multicolumn{5}{|l|}{ Retinal vascular parameters: } \\
\hline CRAE & 123.6 & 120.3 & 2.3 & 0.156 \\
\hline CRVE & 184.3 & 179.7 & 4.6 & 0.325 \\
\hline AVR & 0.676 & 0.673 & 0.014 & 0.818 \\
\hline $\mathrm{FDa}$ & 1.152 & 1.152 & 0.011 & 0.977 \\
\hline FDV & 1.137 & 1.137 & 0.011 & 0.987 \\
\hline cTORTa ${ }^{a}$ & -9.75 & -9.80 & 0.062 & 0.407 \\
\hline cTORTV ${ }^{a}$ & -9.73 & -9.69 & 0.054 & 0.472 \\
\hline
\end{tabular}

Linear regression, corrected for age, sex and diabetes

CI Cognitively Impaired, SE Standard Error of difference, RT Retinal Thickness, RNFL Retinal Nerve Fiber Layer, GCL Ganglion Cell Layer, IPL Inner Plexiform Layer, CRAE Central Retinal Artery Equivalent, CRVE Central Retinal Vein Equivalent, AVR Arteriole-Venular Ratio, FDa Fractal Dimension of arteries, FDv Fractal Dimension of veins, CTORTa curvature Tortuosity of arteries, CTORTV curvature Tortuosity of veins

aLog transformation applied 

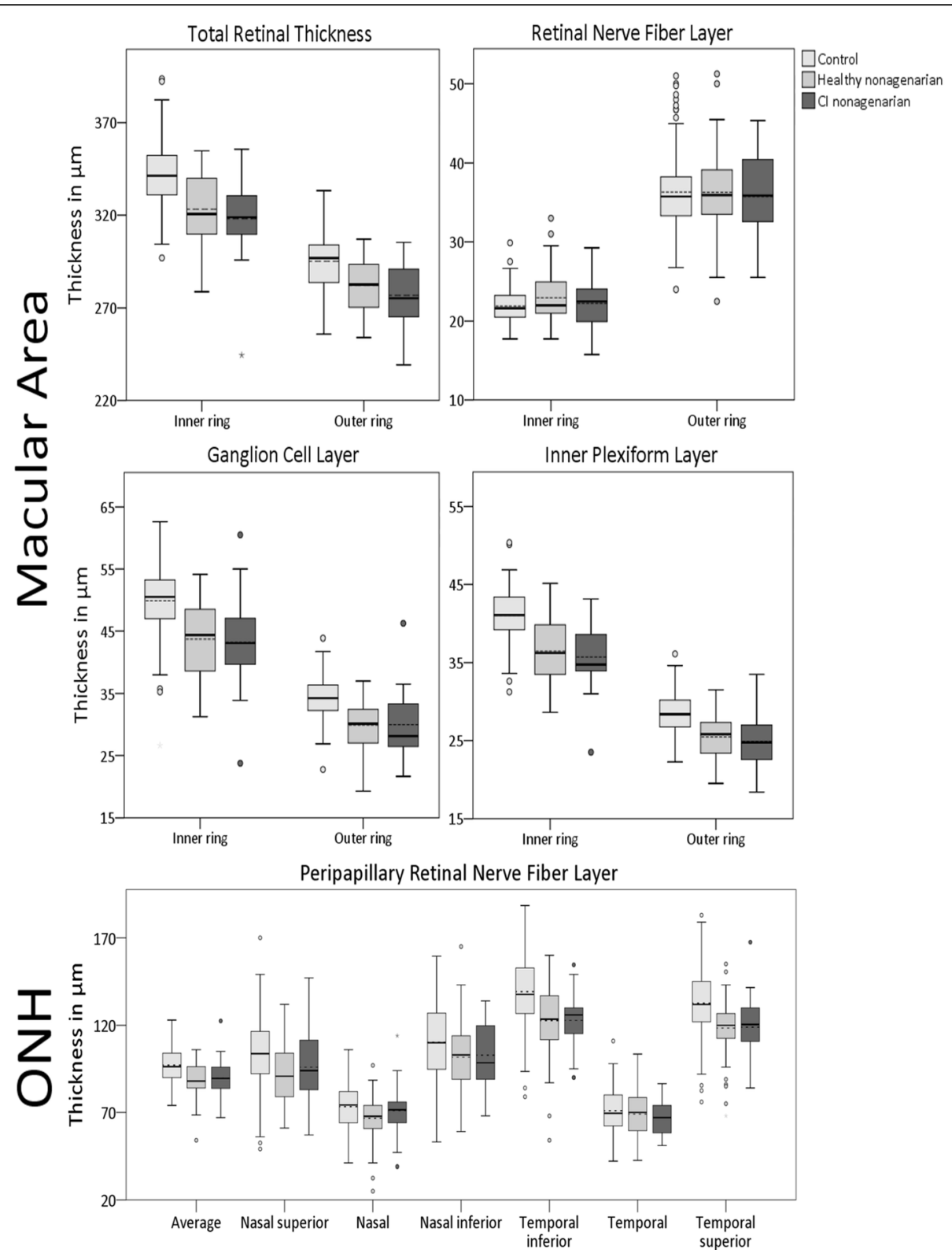

Fig. 1 Boxplots for retinal layer thicknesses as measured with Optical Coherence Tomography in the 3 groups. Dotted line represents the mean. $\mathrm{Cl}=$ Cognitively Impaired, $\mathrm{ONH}=$ Optic Nerve Head

Our analyses showed no statistical difference in any of the studied ocular biomarkers between healthy and CI nonagenarians, suggesting that ocular biomarkers have a limited role in the detection of cognitive impairment in nonagenarians. A possible explanation for the lack of differences may be that other disorders that can have a profound effect on ocular biomarkers (such as hypertension, diabetes and coronary/cardiovascular disease), are also more prevalent in nonagenarians, and may obscure a possible neurodegenerative effect [24-26]. Another explanation can be that other aging related processes affect ocular biomarkers, again obscuring differences between the nonagenarian groups. Indeed, we found that both nonagenarian groups showed large differences in ocular biomarkers, including total/GCL/IPL thickness in the macula, average and most individual segments pRNFL thickness and all retinal vascular parameters except tortuosity (Figs. 1 and 2, Table 3), when compared to younger healthy controls. Several studies showed that aging is associated with thinning of the retina, as well as retinal vascular changes $[15,16,26-30]$. Normal aging unavoidably causes wearing of the body, as is seen in many other organ systems [31]. Especially in nonagenarians, compensatory mechanisms start failing, and such wear and 


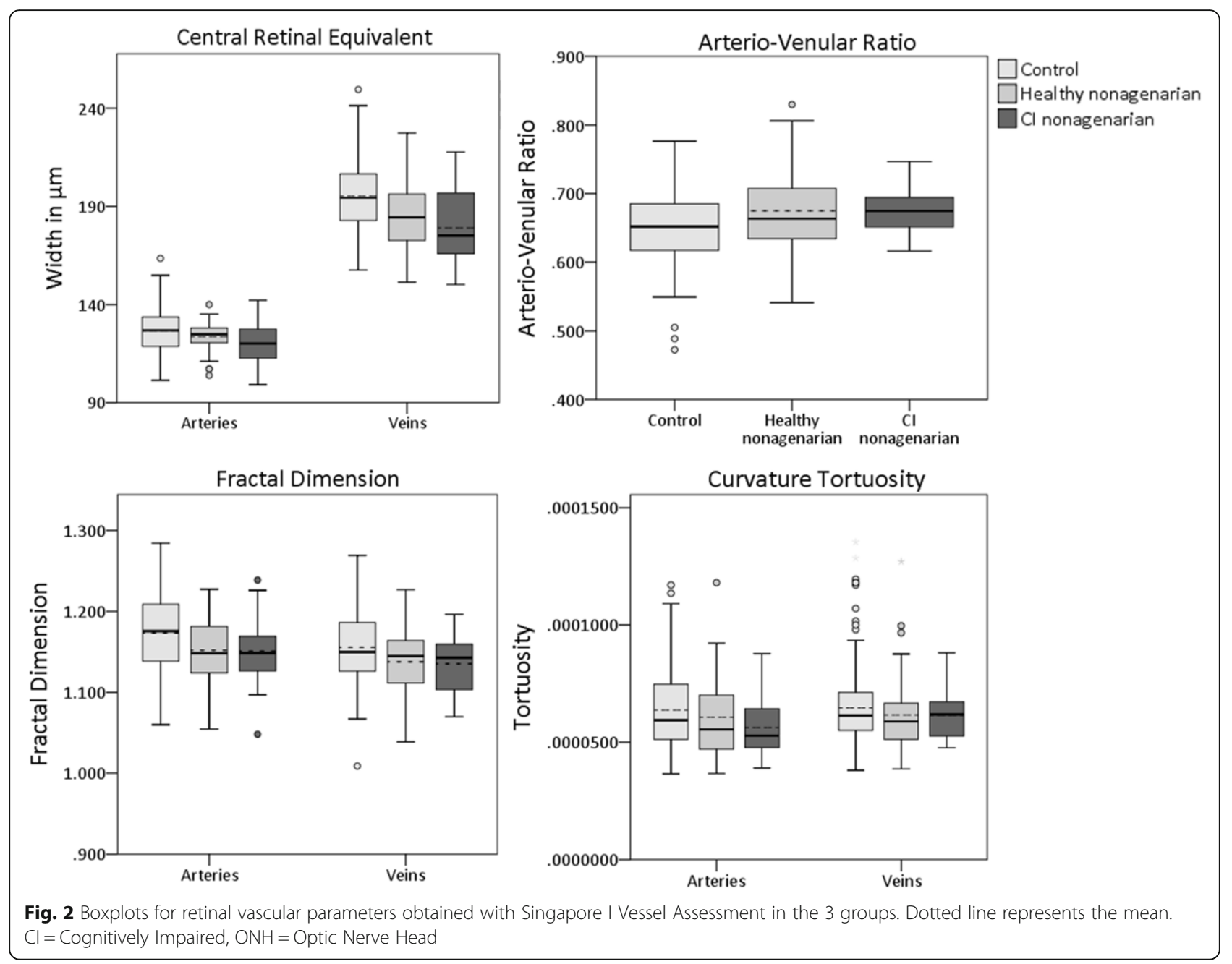

tear effects become more and more pronounced, resulting in multimorbidity [32]. It is likely that this process also occurs in the retina. Blood vessels gradually start to decline due to aging effects like atherosclerosis, causing damage to (micro)vessels, leading to changes in retinal vascular parameters such as thinner vessel calibers and a lower fractal dimension of the vascular network [26]. This in turn may lead to a lower or insufficient blood and oxygen supply, causing damage to the neuronal tissue of the retina, resulting in the thinning of its layers [33,34].

A problem we noticed when performing this study was the difficulty to make reliable images in nonagenarians. In this population there was a very high prevalence of ophthalmological pathology. Some of the diseases were already known at the time of the study and under treatment of an ophthalmologist, but several participants suffered, without their knowing, from ophthalmological pathology requiring medical attention. This resulted in a high exclusion of nonagenarian participants due to bilateral pathology, as illustrated in supplemental fig. 1.
Approximately double the percentage of participants had to be excluded for OCT or SIVA analyses when comparing them with the younger control group. Additionally, acquiring good quality scans/images was harder in the nonagenarian groups, due to their lower endurance, physical impairments and, in the case of CI nonagenarians, cognitive functioning. This suggests that in a substantial $(\sim 25-30 \%)$ percentage of nonagenarians, ocular biomarkers for the diagnosis of dementia cannot be used, due to an inability to obtain reliable images/scans or bilateral ophthalmological pathology being present which interferes with the interpretation of the imaging.

A strength of the study was the extensive characterization of all participants. Participants were comprehensively screened for possible confounding pathologies, and were excluded (e.g. glaucoma, severe AMD, vascular occlusions etc.) or controlled for (diabetes).

Both nonagenarian groups were relatively small, limiting statistical power. Furthermore, as we included nonagenarians that were able to perform the study, which included 2-3 days of assessment (2 days in a hospital 
Table 3 Differences in ocular biomarkers of both nonagenarian groups compared to the younger control group

\begin{tabular}{|c|c|c|c|c|c|c|c|}
\hline & \multirow{2}{*}{$\begin{array}{l}\text { Estimated } \\
\text { marginal } \\
\text { mean of } \\
\text { controls }\end{array}$} & \multicolumn{6}{|c|}{ Mean difference compared to controls } \\
\hline & & Healthy nonagenarians & SE & $p$-value & $\mathrm{Cl}$ nonagenarians & SE & $p$-value \\
\hline \multicolumn{8}{|c|}{ Macular retinal layer thickness: } \\
\hline Total RT inner ring $(\mu \mathrm{m})$ & 340.1 & -18.0 & 3.0 & $<0.001$ & -22.5 & 5.0 & $<0.001$ \\
\hline Total RT outer ring $(\mu \mathrm{m})$ & 294.8 & -12.7 & 2.4 & $<0.001$ & -18.1 & 3.7 & $<0.001$ \\
\hline RNFL inner ring $(\mu \mathrm{m})$ & 21.9 & 1.0 & 0.5 & 0.032 & 0.4 & 0.7 & 0.559 \\
\hline RNFL outer ring $(\mu \mathrm{m})$ & 36.3 & 0.2 & 0.9 & 0.829 & -0.7 & 1.2 & 0.549 \\
\hline $\mathrm{GCL}$ inner ring $(\mu \mathrm{m})$ & 49.8 & -6.1 & 0.9 & $<0.001$ & -6.5 & 1.7 & $<0.001$ \\
\hline GCL outer ring $(\mu \mathrm{m})$ & 34.2 & -4.2 & 0.6 & $<0.001$ & -4.1 & 1.2 & 0.001 \\
\hline IPL inner ring $(\mu \mathrm{m})$ & 41.0 & -4.5 & 0.6 & $<0.001$ & -5.2 & 0.9 & $<0.001$ \\
\hline $\mathrm{IPL}$ outer ring $(\mu \mathrm{m})$ & 28.4 & -2.9 & 0.4 & $<0.001$ & -3.5 & 0.8 & $<0.001$ \\
\hline \multicolumn{8}{|l|}{ Peripapillary RNFL: } \\
\hline Average $(\mu \mathrm{m})$ & 96.9 & -8.6 & 1.6 & $<0.001$ & -7.7 & 2.5 & 0.002 \\
\hline Nasal superior $(\mu \mathrm{m})$ & 103.7 & -13.1 & 3.0 & $<0.001$ & -7.1 & 4.9 & 0.145 \\
\hline Nasal ( $\mu m)$ & 73.3 & -6.5 & 2.3 & 0.004 & -3.1 & 3.3 & 0.349 \\
\hline Nasal inferior $(\mu \mathrm{m})$ & 110.4 & -8.7 & 3.7 & 0.018 & -8.1 & 4.4 & 0.066 \\
\hline Temporal inferior ( $\mu \mathrm{m})$ & 138.6 & -15.4 & 3.3 & $<0.001$ & -16.7 & 4.1 & $<0.001$ \\
\hline Temporal $(\mu \mathrm{m})$ & 70.7 & -1.4 & 2.0 & 0.486 & -4.1 & 2.5 & 0.108 \\
\hline Temporal superior $(\mu \mathrm{m})$ & 132.2 & -13.5 & 2.9 & $<0.001$ & -13.8 & 4.1 & 0.001 \\
\hline \multicolumn{8}{|l|}{ Retinal vascular parameters: } \\
\hline CRAE & 126.8 & -3.1 & 1.5 & 0.038 & -6.4 & 2.4 & 0.009 \\
\hline CRVE & 195.3 & -10.9 & 3.0 & $<0.001$ & -14.4 & 4.2 & 0.001 \\
\hline AVR & 0.652 & 0.024 & 0.010 & 0.013 & 0.017 & 0.009 & 0.045 \\
\hline $\mathrm{FDa}$ & 1.173 & -0.021 & 0.007 & 0.003 & -0.021 & 0.010 & 0.035 \\
\hline FDV & 1.156 & -0.019 & 0.007 & 0.009 & -0.018 & 0.009 & 0.040 \\
\hline CTORTa ${ }^{a}$ & -9.690 & -0.057 & 0.041 & 0.171 & -0.109 & 0.054 & 0.045 \\
\hline cTORTV ${ }^{a}$ & -9.670 & -0.054 & 0.038 & 0.153 & -0.031 & 0.041 & 0.445 \\
\hline
\end{tabular}

Values in bold are significant at $p<0.05$

GEE corrected for sex and a diabetes, SE Standard Error, Cl Cognitively Impaired, RT Retinal Thickness, RNFL Retinal Nerve Fiber Layer, GCL Ganglion Cell Layer, IPL Inner Plexiform Layer, CRAE Central Retinal Artery Equivalent, CRVE Central Retinal Vein Equivalent, AVR Arteriole-Venular Ratio, FDa Fractal Dimension of arteries, FDv Fractal Dimension of veins, cTORTa curvature Tortuosity of arteries, cTORTV curvature Tortuosity of veins

${ }^{\mathrm{a}}$ Log transformation applied

setting), this could also have introduced a bias, as only relatively healthy individuals of this older population will have been included in this study.

\section{Conclusion}

We found no significant differences between the healthy and $\mathrm{CI}$ nonagenarian groups for any of the studied ocular biomarkers. We did find significant differences in 19 out of 22 of the ocular biomarkers assessed in this study when comparing either nonagenarian group to a healthy younger control grouper, suggesting a large effect of age on these biomarkers. The combination of these findings, along with the difficulties we encountered in obtaining suitable images in our nonagenarian population, leads to the conclusion that the use of ocular biomarkers in a population of the oldest-old is very limited.

\section{Supplementary information}

Supplementary information accompanies this paper at https://doi.org/10 1186/s12877-020-01556-1.

Additional file 1. Reasons for excluding participants, categorized per group. Note that participants were only excluded if bilateral problems were present, explaining why the total $\mathrm{N}$ may be lower than the subdivided numbers taken together (i.e. 1 eye of a participant may fall in 1 category, and the contralateral eye in another). Cl= Cognitively Impaired, OCT = Optical Coherence Tomography, SIVA = Singapore I Vessel Assessment, AMD = Age-related Macular Degeneration, ERM= Epiretinal Membrane, PPA = Peripapillary Atrophy, $\mathrm{CSC}=$ Central Serous Chorioretinopathy.

\section{Abbreviations}

AD: Alzheimer's Disease; aMCl: amnestic Mild Cognitive Impairment; AMD: Age-related Macular Degeneration; AVR: Arteriole-Venular Ratio; BCVA: Best Corrected Visual Acuity; CDR: Clinical Dementia Rating; CERAD: Consortium to Establish a Registry for Alzheimer's Disease; 
Cl: Cognitively Impaired; CRAE: Central Retinal Artery Equivalent; CRVE: Central Retinal Vein Equivalent; CTORTa: Curvature Tortuosity of arteries; cTORTV: Curvature Tortuosity of veins; ETDRS: Early Treatment and Diabetic Retinopathy Study; FDa: Fractal Dimension of arteries; FDv: Fractal Dimension of veins; GCL: Ganglion Cell Layer; GDS: Geriatric Depression Scale; GEE: Generalized Estimating Equations; IPL: Inner Plexiform Layer; MMSE: Mini Mental State Exam; OCT: Optical Coherence Tomography; ONH: Optic Nerve Head; pRNFL: peripapillary Retinal Nerve Fiber Layer; RNFL: Retinal Nerve Fiber Layer; RT: Retinal Thickness; SIVA: Singapore I Vessel Assessment; TICS-m: Telephone Interview for Cognitive Status modified

\section{Acknowledgements}

Not applicable.

\section{Authors' contributions}

JAvdK wrote the manuscript, acquired data, analyzed the results, interpreted the data and contributed to the conception and design of the work. NL and HTN acquired data, contributed to the conception and design of the work and critically revised the manuscript. MB, EK, JT and MtK acquired data and critically revised the manuscript. AdB and ABM contributed to the conception and design of the work and critically revised the manuscript. HST critically revised the manuscript. FDV and PJV interpreted the data, contributed to the conception and design of the work and critically revised the manuscript. All authors read and approved the final manuscript.

\section{Funding}

This work has received support from the EU/EFPIA Innovative Medicines Initiative Joint Undertaking (EMIF grant number 115372).

These funding sources had no involvement in the collection, analysis and interpretation of data; in the writing of the report; or in the decision to submit the article for publication.

\section{Availability of data and materials}

The datasets used and/or analyzed during the current study are available from the corresponding author on reasonable request.

\section{Ethics approval and consent to participate}

The study adhered the Tenets of the Declaration of Helsinki and written informed consent was obtained from all participants. The Medical Ethics Committee of the Amsterdam UMC approved the study.

\section{Consent for publication}

Not applicable.

\section{Competing interests}

Pieter Jelle Visser is a member of the editorial board (section editor) of BMC Geriatrics. None of the other authors have competing interests.

\section{Author details}

'Ophthalmology Department, Amsterdam UMC, location VUmc, De Boelelaan 1117, 1081HV Amsterdam, The Netherlands. ${ }^{2}$ Alzheimer Center Amsterdam, Department of Neurology, Amsterdam Neuroscience, Vrije Universiteit Amsterdam, Amsterdam UMC, Amsterdam, The Netherlands. ${ }^{3}$ Department of Biological Psychology, VU University Amsterdam, Amsterdam, The Netherlands. ${ }^{4}$ Department of Medicine and Aged Care, @AgeMelbourne, Royal Melbourne Hospital, University of Melbourne, Melbourne, Australia. ${ }^{5}$ Department of Human Movement Sciences, @AgeAmsterdam, Amsterdam Movement Sciences, Vrije Universiteit Amsterdam, Amsterdam, The Netherlands.

\section{Received: 16 May 2019 Accepted: 13 April 2020}

Published online: 28 April 2020

\section{References}

1. London A, Benhar I, Schwartz M. The retina as a window to the brain-from eye research to CNS disorders. Nat Rev Neurol. 2013;9(1):44-53.

2. Jindal V. Interconnection between brain and retinal neurodegenerations. Mol Neurobiol. 2015;51(3):885-92.

3. Chan VIT, Sun Z, Tang S, Chen L, Wong A, Tham CC, Wong TY, Chen C, Ikram MK, Whitson HE, et al. Spectral-domain OCT measurements in
Alzheimer's disease: a systematic review and meta-analysis. Ophthalmology. 2019;126(4):497-510.

4. Chhablani PP, Ambiya V, Nair AG, Bondalapati S, Chhablani J. Retinal findings on OCT in systemic conditions. Semin Ophthalmol. 2018;33(4):525-46.

5. den Haan J, Verbraak FD, Visser PJ, Bouwman FH. Retinal thickness in Alzheimer's disease: a systematic review and meta-analysis. Alzheimers Dement (Amst). 2017;6:162-70.

6. Frost S, Martins RN, Kanagasingam Y. Ocular biomarkers for early detection of Alzheimer's disease. J Alzheimers Dis. 2010;22(1):1-16.

7. Lim JK, Li QX, He Z, Vingrys AJ, Wong VH, Currier N, Mullen J, Bui BV, Nguyen CT. The eye as a biomarker for Alzheimer's disease. Front Neurosci. 2016;10:536.

8. McGrory S, Cameron JR, Pellegrini E, Warren C, Doubal FN, Deary IJ, Dhillon B, Wardlaw JM, Trucco E, MacGillivray TJ. The application of retinal fundus camera imaging in dementia: a systematic review. Alzheimers Dement (Amst). 2017;6:91-107.

9. Cheung CY, Hsu W, Lee ML, Wang JJ, Mitchell P, Lau QP, Hamzah H, Ho M, Wong TY. A new method to measure peripheral retinal vascular caliber over an extended area. Microcirculation. 2010;17(7):495-503.

10. Cheung CY, Tay WT, Mitchell P, Wang JJ, Hsu W, Lee ML, Lau QP, Zhu AL, Klein R, Saw SM, et al. Quantitative and qualitative retinal microvascular characteristics and blood pressure. J Hypertens. 2011;29(7):1380-91.

11. Cheung CY, Zheng Y, Hsu W, Lee ML, Lau QP, Mitchell P, Wang JJ, Klein R, Wong TY. Retinal vascular tortuosity, blood pressure, and cardiovascular risk factors. Ophthalmology. 2011;118(5):812-8.

12. Corrada MM, Brookmeyer R, Berlau D, Paganini-Hill A, Kawas CH. Prevalence of dementia after age 90: results from the 90+ study. Neurology. 2008;71(5): 337-43.

13. LoGiudice D, Watson R. Dementia in older people: an update. Intern Med J. 2014;44(11):1066-73

14. Yang Z, Slavin MJ, Sachdev PS. Dementia in the oldest old. Nat Rev Neurol. 2013:9(7):382-93.

15. Wei Y, Jiang H, Shi Y, Qu D, Gregori G, Zheng F, Rundek T, Wang J. Agerelated alterations in the retinal microvasculature, microcirculation, and microstructure. Invest Ophthalmol Vis Sci. 2017;58(9):3804-17.

16. Demirkaya N, van Dijk HW, van Schuppen SM, Abramoff MD, Garvin MK Sonka M, Schlingemann RO, Verbraak FD. Effect of age on individual retinal layer thickness in normal eyes as measured with spectral-domain optical coherence tomography. Invest Ophthalmol Vis Sci. 2013;54(7):4934-40.

17. Legdeur N, Badissi M, Carter SF, de Crom S, van de Kreeke A, Vreeswijk R, Trappenburg MC, Oudega ML, Koek HL, van Campen JP, et al. Resilience to cognitive impairment in the oldest-old: design of the EMIF-AD $90+$ study. BMC Geriatr. 2018;18(1):289.

18. Konijnenberg E, Carter SF, Ten Kate M, den Braber A, Tomassen J, Amadi C, Wesselman L, Nguyen HT, van de Kreeke JA, Yaqub M, et al. The EMIF-AD PreclinAD study: study design and baseline cohort overview. Alzheimers Res Ther. 2018;10(1):75.

19. Boomsma DI, de Geus EJ, Vink JM, Stubbe JH, Distel MA, Hottenga JJ, Posthuma D, van Beijsterveldt TC, Hudziak JJ, Bartels M, et al. Netherlands twin register: from twins to twin families. Twin Res Hum Genet. 2006;9(6):849-57.

20. Petersen RC. Mild cognitive impairment as a diagnostic entity. J Intern Med. 2004;256(3):183-94.

21. McKhann G, Drachman D, Folstein M, Katzman R, Price D, Stadlan EM. Clinical diagnosis of Alzheimer's disease: report of the NINCDS-ADRDA work group under the auspices of Department of Health and Human Services Task Force on Alzheimer's disease. Neurology. 1984;34(7):939-44.

22. van de Kreeke JA, Nguyen HT, den Haan J, Konijnenberg E, Tomassen J, den Braber A, Ten Kate M, Collij L, Yaqub M, van Berckel B, et al. Retinal layer thickness in preclinical Alzheimer's disease. Acta Ophthalmol. 2019;97(8): 798-804.

23. van de Kreeke JA, Nguyen HT, Konijnenberg E, Tomassen J, den Braber A, Ten Kate M, Sudre CH, Barkhof F, Boomsma DI, Tan HS, et al. Retinal and cerebral microvasculopathy: relationships and their genetic contributions. Invest Ophthalmol Vis Sci. 2018;59(12):5025-31.

24. De Clerck EE, Schouten JS, Berendschot TT, Kessels AG, Nuijts RM, Beckers HJ, Schram MT, Stehouwer CD, Webers CA. New ophthalmologic imaging techniques for detection and monitoring of neurodegenerative changes in diabetes: a systematic review. Lancet Diabetes Endocrinol. 2015;3(8):653-63.

25. Ikram MK, Ong YT, Cheung CY, Wong TY. Retinal vascular caliber measurements: clinical significance, current knowledge and future perspectives. Ophthalmologica. 2013;229(3):125-36. 
26. Wang SB, Mitchell P, Liew G, Wong TY, Phan K, Thiagalingam A, Joachim N, Burlutsky G, Gopinath B. A spectrum of retinal vasculature measures and coronary artery disease. Atherosclerosis. 2018;268:215-24.

27. Hoffmann EM, Schmidtmann I, Siouli A, Schuster AK, Beutel ME, Pfeiffer N, Lamparter J. The distribution of retinal nerve fiber layer thickness and associations with age, refraction, and axial length: the Gutenberg health study. Graefes Arch Clin Exp Ophthalmol. 2018;256(9):1685-93.

28. Won JY, Kim SE, Park YH. Effect of age and sex on retinal layer thickness and volume in normal eyes. Medicine (Baltimore). 2016;95(46):e5441.

29. Huang QF, Wei FF, Zhang ZY, Raaijmakers A, Asayama K, Thijs L, Yang WY, Mujaj B, Allegaert K, Verhamme P, et al. Reproducibility of retinal microvascular traits decoded by the Singapore I vessel assessment software across the human age range. Am J Hypertens. 2018;31(4):438-49.

30. Leung H, Wang JJ, Rochtchina E, Tan AG, Wong TY, Klein R, Hubbard LD, Mitchell P. Relationships between age, blood pressure, and retinal vessel diameters in an older population. Invest Ophthalmol Vis Sci. 2003;44(7): 2900-4.

31. Wyss-Coray T. Ageing, neurodegeneration and brain rejuvenation. Nature. 2016;539(7628):180-6.

32. Formiga F, Ferrer A, Sanz H, Marengoni A, Alburquerque J, Pujol R, Octabaix study $\mathrm{m}$. Patterns of comorbidity and multimorbidity in the oldest old: the Octabaix study. Eur J Intern Med. 2013;24(1):40-4.

33. Frydkjaer-Olsen U, Soegaard Hansen R, Pedersen K, Peto T, Grauslund J. Retinal vascular fractals correlate with early Neurodegeneration in patients with type 2 diabetes mellitus. Invest Ophthalmol Vis Sci. 2015; 56(12):7438-43.

34. Lasta M, Pemp B, Schmidl D, Boltz A, Kaya S, Palkovits S, Werkmeister R, Howorka K, Popa-Cherecheanu A, Garhofer G, et al. Neurovascular dysfunction precedes neural dysfunction in the retina of patients with type 1 diabetes. Invest Ophthalmol Vis Sci. 2013;54(1):842-7.

\section{Publisher's Note}

Springer Nature remains neutral with regard to jurisdictional claims in published maps and institutional affiliations.

Ready to submit your research? Choose BMC and benefit from:

- fast, convenient online submission

- thorough peer review by experienced researchers in your field

- rapid publication on acceptance

- support for research data, including large and complex data types

- gold Open Access which fosters wider collaboration and increased citations

- maximum visibility for your research: over $100 \mathrm{M}$ website views per year

At $\mathrm{BMC}$, research is always in progress.

Learn more biomedcentral.com/submissions 